\title{
Association of Signal Transducer and Activator of Transcription 4 rs10181656 Polymorphism With Rheumatoid Arthritis and Systemic Sclerosis in Khuzestan Province in Southwestern Iran
}

\author{
Fatemeh GHANAVATI ${ }^{1}$, Seyed Reza Kazemi NEZHAD ${ }^{1}$, \\ Mohammad Reza HAJJARI' (D), Mohammad Reza AKHOOND² ${ }^{\text {ID }}$ \\ ${ }^{1}$ Department of Genetics, Faculty of Science, Shahid Chamran University of Ahvaz, Ahvaz, Iran \\ ${ }^{2}$ Department of Statistics, Faculty of Mathematics and Computer Science, Shahid Chamran University of Ahvaz, Ahvaz, Iran
}

\begin{abstract}
Objectives: This study aims to investigate the association of polymorphism rs10181656 (C>G) of signal transducer and activator of transcription 4 (STAT4) gene with rheumatoid arthritis (RA) and systemic sclerosis (SSc) in the southwest of Iran as well as the probable relationship between the polymorphism with clinical features and disease activity parameters in both diseases.

Patients and methods: A total of 200 patients (120 with RA [21 males, 99 females; mean age 44.83 years; range, 16 to 75 years] and 80 with SSc [13 males, 67 females; mean age 44.3 years; range, 30 to 75 years]) and 120 healthy controls ( 25 males, 95 females; mean age 46.93 years; range, 30 to 75 years) were recruited in this study. Genotyping was performed by polymerase chain reaction-restriction fragment length polymorphism. A set of genotypes was confirmed by sequencing.

Results: A statistically significant association was detected between STAT4 rs10181656 polymorphism and RA ( $p=0.007$ ). No significant correlation was detected between STAT4 rs 10181656 polymorphism and SSc $(p=0.357)$. None of the clinical features (anti-cyclic citrullinated peptide, rheumatoid factor) or disease activity parameters (limited cutaneous SSc, diffuse cutaneous SSc) showed any correlation with the genotype distribution of the STAT4 rs10181656 polymorphism in RA or SSc patients.

Conclusion: Our findings suggest an association between RA susceptibility and STAT4 rs10181656 polymorphism. However, no significant association was found between the mentioned polymorphism and SSc. Clinical features and disease activity parameters did not show any association with the polymorphism.

Keywords: Anti-cyclic citrullinated peptide, rheumatoid arthritis, rheumatoid factor, STAT4, systemic sclerosis.
\end{abstract}

Autoimmune diseases are a various group of complex diseases caused by loss of immunologic tolerance to self-antigens leading to immunemediated destruction of tissues and organs. The diseases affect up to about $5 \%$ of the world population. ${ }^{1}$ The pathogenesis of autoimmune diseases has been widely considered to be multifactorial, with genetics, epigenetics, and environmental factors involved in disease onset and progression. ${ }^{2}$ These diseases constitute a group of several complex disorders, such as rheumatoid arthritis (RA), systemic sclerosis (SSc), psoriasis and celiac disease.

Recent studies have shown that many autoimmune diseases share similar immune pathogenesis. ${ }^{3}$ RA and SSc are autoimmune diseases characterized by the development of immune response against self-antigens and

Received: December 27, 2018 Accepted: March 04, 2019 Published online: April 26, 2019

Correspondence: Seyed Reza Kazemi Nezhad, PhD. Department of Genetics, Faculty of Science, Shahid Chamran University of Ahvaz, $61357-43337$ Ahvaz, Iran. Tel: +986133738401 e-mail:kazemi_reza@scu.ac.ir rheumatoid arthritis and systemic sclerosis in khuzestan province in southwestern iran. Arch Rheumatol 2019;34(4):434-442. 
inflammatory factors. Although their etiology remains a mystery, $\mathrm{RA}$ and $\mathrm{SSc}$ share a few similar pathogenic mechanisms. ${ }^{4}$

Rheumatoid arthritis is phenotypically heterogeneous. It is a systemic autoimmune disease characterized by chronic destructive inflammation in synovial joints, leading to progressive joint damage. ${ }^{5}$ The disease can be subdivided into two groups (autoantibody positive or autoantibody negative) according to the presence or absence of either rheumatoid factor (RF) or anti-cyclic citrullinated peptide (anti-CCP). ${ }^{5} \mathrm{RA}$ affects about $0.5-1 \%$ of the adult population worldwide and is higher among females than males. ${ }^{6}$ The etiology of RA is still unknown, but it is thought to have both genetic and environmental basis.?

Systemic sclerosis is a rare multifaceted autoimmune disease. Its main manifestations are immune activation, vasculopathy, and ultimately extensive fibrosis of the skin and internal organs. ${ }^{8}$ One of the central events responsible for SSc development is the dysregulation of the immune system. The altered immune response in SSc is marked by an increased $\mathrm{T}$ cell activation and the secretion of pro-inflammatory mediators that contribute to the generation of fibrosis and endothelial alterations. Based on the extent of skin involvement, SSc is classified into limited cutaneous SSc (lcSSc) and diffuse cutaneous SSc (dcSSc). ${ }^{8,9}$ It should be noted that the relative risk of developing SSc remains rather low, 1.6\% in families versus $0.026 \%$ in the general population. ${ }^{10}$

Until now, shared susceptibility genetic loci have been documented to be associated with multiple autoimmune diseases, including the genetic major histocompatibility complex (MHC) and non-MHC polymorphisms. ${ }^{11}$ However, except for MHC alleles associated with nearly all known autoimmune diseases in diverse populations, identifying non-MHC susceptibility genetic variants has remained to be challenging. Among the second group, the association between the Arg620 $\rightarrow$ Trp variant of the PTPN22 gene and RA has already been documented in several studies. $^{12}$

The signal transducer and activator of transcription 4 (STAT4) maps to chromosome 2q33. This gene produces a transcription factor which is involved in intracellular signals activated by some cytokines such as interleukin (IL)-12,
IL-23, IL-27 and type I interferons. The gene is expressed in different cells such as dendritic cells, activated peripheral blood monocytes, and macrophages at the sites of inflammation. ${ }^{12,13}$

Cytosolic STAT4 can be phosphorylated to form a homodimer which translocates to the nucleus. ${ }^{14,15}$ STAT4 has a deoxyribonucleic acid (DNA)-binding domain and specifically binds to several DNA sequences among the promoter regions of cytokine genes as well as receptors and signal factors. ${ }^{16}$

To date, four polymorphisms in the third intron of STAT4 gene (rs11889341, rs7574865, rs8179673, and rs10181656) have been found to be associated with increased risk of diverse complex autoimmune diseases even in different ethnic populations. The diseases include $\mathrm{SSc},{ }^{17}$ RA, and Sjögren's syndrome. ${ }^{18}$ Studies suggest that STAT4 may be an "autoimmune disease susceptibility gene" and support the concept of common dysregulated pathways across multiple autoimmune diseases.

To our knowledge, this single nucleotide polymorphism (SNP) has not been previously tested in the Khuzestan province in Southwestern Iran. Thus this population study can be of great importance. Therefore, in this study, we aimed to investigate the association of polymorphism rs10181656 (C>G) of STAT4 gene with RA and $\mathrm{SSc}$ in the southwest of Iran as well as the probable relationship between the polymorphism with clinical features and disease activity parameters in both diseases.

\section{PATIENTS AND METHODS}

This study was conducted at Shahid Chamran University of Ahvaz between August 2017 and August 2018. The study included 200 patients (120 with RA [21 males, 99 females; mean age 44.83 years; range, 16 to 75 years] and 80 with SSc [13 males, 67 females; mean age 44.3 years; range, 30 to 75 years]) and 120 healthy controls (25 males, 95 females; mean age 46.93 years; range, 30 to 75 years). Participants of the study were matched by geographic region, age and sex. The population was composed of a case-control set from Khuzestan province in the Southwest of Iran including Arab and non-Arab populations. 
The study protocol was approved by the Shahid Chamran University of Ahvaz Ethics Committee. A written informed consent was obtained from each participant. The study was conducted in accordance with the principles of the Declaration of Helsinki.

The RA and SSc patients were classified according to the American College of Rheumatology (ACR) criteria. Detailed clinical and laboratory information was provided from the patients of the Rheumatology Clinic at Golstan Hospital in Ahvaz, Iran. A questionnaire was supplied regarding parameters such as ethnicity, sex, positive family history and age. Clinical parameters were estimated using the commercially available enzyme linked immunosorbent assay kits for anti-CCP and RF. RF measured to be $>20 \mathrm{IU} / \mathrm{mL}$ was considered as RF positive. The presence of anti-CCP was determined and a cutoff point of $>5 \mathrm{U} / \mathrm{mL}$ was used as a stringent criterion for anti-CCP positivity.

Clinical symptoms of SSc were diagnosed based on the ACR criteria by a specialist. Preliminary criteria for disease classification included having at least three of the five features of the CREST syndrome (calcinosis, Raynaud's phenomenon, esophageal dysmotility, sclerodactyly, and telangiectasias). SSc patients were further classified based on diffuse or limited skin involvement and by autoantibody status. A questionnaire was supplied for the SSc patients, too.

Subjects of the control group were selected from the Golstan Hospital. None of the subjects had any family history of autoimmune diseases.
They were recruited from the same geographic region to be genotyped and compared with the patients in the designed study. A questionnaire was filled for each subject.

Whole blood was collected in ethylenediaminetetraacetic acid containing tubes. Genomic DNA was isolated using standard salting-out method. The quality and quantity of genomic DNA were determined by agarose gel electrophoresis and ultraviolet (UV) spectrophotometer measuring absorption at 260 and $280 \mathrm{~nm}$ wavelengths. DNA was stored at $-20^{\circ} \mathrm{C}$ until analysis. Genotyping was performed by polymerase chain reaction-restriction fragment length polymorphism (PCR-RFLP) technique. A set of genotypes was confirmed by direct DNA sequencing. The upstream primer 5'-AGTTT TCAAAGTCTAACACTGTG-3' and downstream primer 5'-TACTCTCGACATGGCAGC-3' were used to amplify the region of interest (TAG Copenhagen, Frederiksberg, Denmark).

The PCR was carried out in a total volume of $25 \mu \mathrm{L}$ containing $100-200 \mathrm{ng}$ of genomic DNA, $12.5 \mu \mathrm{L}$ mastermix, $1 \mu \mathrm{L}$ of each primer $(10 \mu \mathrm{M}), 2 \mu \mathrm{L}$ deoxynucleotide triphosphate (5 $\mathrm{mM})$ and $8.5 \mu \mathrm{L}$ water. Amplification was performed with a denaturation step at $95^{\circ} \mathrm{C}$ for three minutes, followed by 35 cycles of denaturation at $95^{\circ} \mathrm{C}$ for 30 seconds, annealing at $57^{\circ} \mathrm{C}$ for 45 seconds and extension at $72^{\circ} \mathrm{C}$ for 45 seconds. The final extension step at $72^{\circ} \mathrm{C}$ was performed for five minutes. Three to five $\mu \mathrm{L}$ of $\mathrm{PCR}$ products were run on $1.5 \%$

\begin{tabular}{|c|c|c|c|c|c|c|c|}
\hline & \multicolumn{2}{|c|}{ RA patients $(n=120)$} & \multicolumn{2}{|c|}{ Controls $(n=120)$} & \multirow[b]{2}{*}{$p$} & \multirow[b]{2}{*}{ OR } & \multirow[b]{2}{*}{$95 \% \mathrm{CI}$} \\
\hline & $\mathrm{n}$ & $\%$ & $\mathrm{n}$ & $\%$ & & & \\
\hline \multicolumn{8}{|c|}{ Genotype } \\
\hline $\mathrm{CC}$ & 74 & 56.5 & 57 & 43.5 & - & - & - \\
\hline CG & 32 & 36.8 & 55 & 63.2 & 0.005 & 0.448 & $0.257-0.781$ \\
\hline GG & 14 & 63.6 & 8 & 36.4 & 0.531 & 1.348 & $0.529-3.433$ \\
\hline \multicolumn{8}{|l|}{ Allele } \\
\hline $\mathrm{C}$ & 180 & 51.6 & 169 & 48.4 & - & 1 & - \\
\hline G & 60 & 45.8 & 71 & 54.2 & 0.260 & 1.261 & $0.842-1.886$ \\
\hline
\end{tabular}




\begin{tabular}{|c|c|c|c|c|c|c|c|}
\hline & \multicolumn{2}{|c|}{ SSc patients $(n=120)$} & \multicolumn{2}{|c|}{ Controls $(n=120)$} & \multirow[b]{2}{*}{$p$} & \multirow[b]{2}{*}{ OR } & \multirow[b]{2}{*}{$95 \% \mathrm{CI}$} \\
\hline & $\mathrm{n}$ & $\%$ & $\mathrm{n}$ & $\%$ & & & \\
\hline \multicolumn{8}{|c|}{ Genotype } \\
\hline $\mathrm{CC}$ & 37 & 46.3 & 57 & 47.5 & - & - & - \\
\hline CG & 33 & 41.3 & 55 & 45.8 & 0.796 & 0.924 & $0.508-1.681$ \\
\hline GG & 10 & 12.5 & 8 & 6.7 & 0.207 & 1.926 & $0.696-5.328$ \\
\hline Allele & & & & & & & - \\
\hline C & 107 & 66.9 & 169 & 70.4 & - & 1 & - \\
\hline G & 55 & 33.1 & 71 & 29.6 & 0.435 & 0.848 & $0.551-1.304$ \\
\hline
\end{tabular}

agarose gel to observe the target band before performing the restriction digestion reaction. Digestion was performed in a total volume of $31 \mu \mathrm{L}$, containing $10 \mu \mathrm{L}$ of PCR products, 1 unit of Ddel enzyme (10 Units/ $\mu \mathrm{L}$, Thermo Fisher Scientific Inc., Waltham, Massachusetts, ABD), $2 \mu \mathrm{L} 10 \times$ enzyme buffer and $10 \mu \mathrm{L}$ of nuclease-free water. Digestion reaction was incubated at $37^{\circ} \mathrm{C}$ overnight. Digested products were analyzed by running on 3\% agarose gel next to ultra-low range
DNA ladder (Fermentas, Hennigsdorf, Germany), stained by ethidium bromide, visualized under UV light and photographed. Direct sequencing of PCR products was performed by Macrogen Inc. (Seoul, South Korea).

\section{Statistical analysis}

Hardy-Weinberg equilibrium was tested using the Hardy-Weinberg package (http://CRAN. Rproject.org $/$ package $=$ HardyWeinberg). For

Table 3. Demographic and clinical characteristics of RA and SSc patients

\begin{tabular}{|c|c|c|c|c|c|c|c|c|c|}
\hline & \multicolumn{3}{|c|}{ RA patients $(\mathrm{n}=120)$} & \multicolumn{3}{|c|}{ SSc patients $(n=80)$} & \multicolumn{3}{|c|}{ Controls $(n=120)$} \\
\hline & $\mathrm{n}$ & $\%$ & Mean \pm SD & $\mathrm{n}$ & $\%$ & Mean \pm SD & $\mathrm{n}$ & $\%$ & Mean \pm SD \\
\hline \multicolumn{10}{|c|}{ Demographic characteristics } \\
\hline Age (year) & & & $44.8 \pm 11.9$ & & & $44.3 \pm 11.3$ & & & $46.9 \pm 11.9$ \\
\hline $\begin{array}{l}\text { Sex } \\
\quad \text { Females } \\
\text { Males }\end{array}$ & $\begin{array}{l}99 \\
21\end{array}$ & $\begin{array}{l}82.5 \\
17.5\end{array}$ & & $\begin{array}{l}67 \\
13\end{array}$ & $\begin{array}{l}63.7 \\
16.3\end{array}$ & & $\begin{array}{l}95 \\
25\end{array}$ & $\begin{array}{l}79.2 \\
20.8\end{array}$ & \\
\hline \multicolumn{10}{|l|}{ Clinical characteristics } \\
\hline Disease duration (year) & & & $7.2 \pm 6.3$ & & & & & & \\
\hline $\begin{array}{l}\text { Anti-CCP Ab positive } \\
\text { Total patients }\end{array}$ & $\begin{array}{c}79 \\
120\end{array}$ & 66 & & & & & & & \\
\hline $\begin{array}{l}\text { Anti-CCP Ab negative } \\
\text { Total patients }\end{array}$ & $\begin{array}{c}41 \\
120\end{array}$ & 34 & & & & & & & \\
\hline $\begin{array}{l}\text { RF positive } \\
\text { Total patients }\end{array}$ & $\begin{array}{c}42 \\
120\end{array}$ & 35 & & & & & & & \\
\hline $\begin{array}{l}\text { RF negative } \\
\text { Total patients }\end{array}$ & $\begin{array}{c}78 \\
120\end{array}$ & 65 & & & & & & & \\
\hline lcSSc (lcSSc/total patients) & & & & $\begin{array}{l}31 \\
80\end{array}$ & 38.75 & & & & \\
\hline dcSSc (lcSSc/total patients) & & & & $\begin{array}{l}49 \\
80 \\
\end{array}$ & 61.25 & & & & \\
\hline
\end{tabular}




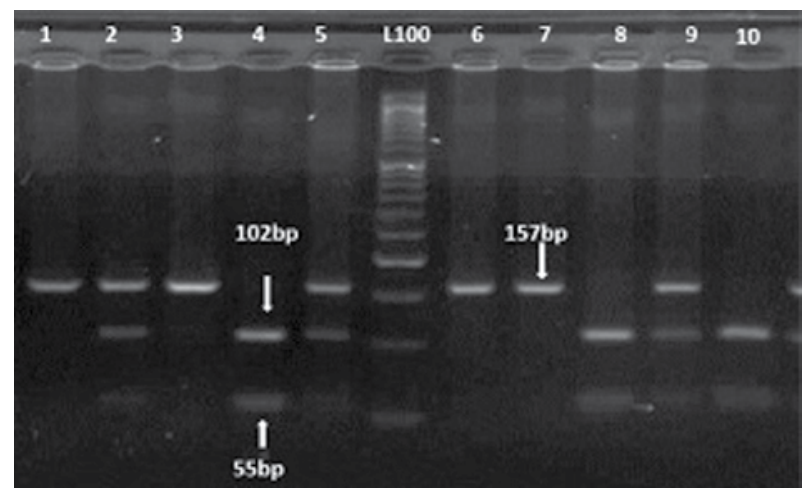

Figure 1. Restriction fragment length polymorphism analysis including rs10181656 column L100 is 100 bp marker, columns 4, 8 and 10 are GG wild homozygote samples shown at $102 \mathrm{bp}$ and $55 \mathrm{bp}$, columns 2, 5 and 9 are GC heterozygote samples and column 1, 3, 6 and 7 are CC mutated homozygote genotypes that appear at $157 \mathrm{bp}$.

genotypic and allelic frequencies, Chi-square test and Spearman's correlation test were used (the PASW version 18.0, SPSS Inc., Chicago, IL, USA). Results were given as mean values, standard deviation and minimum and maximum scores. Odds ratio (OR) and 95\% confidence intervals (CIs) were also calculated. In each test, a p value of less than 0.05 was considered statistically significant.

\section{RESULTS}

The genotypic and allelic frequencies of the rs10181656 STAT4 gene polymorphism in RA, SSc patients and controls are shown in Tables 1 and 2. Genotype frequency for the STAT4 rs10181656 polymorphism was in Hardy-Weinberg equilibrium in SSc patients and control cohorts. Our results showed a statistically significant association between STAT4 rs10181656 polymorphism and RA $(p=0.007)$. Moreover, no significant difference in allele frequency was detected between RA patients and control group $(p=0.260)$. The comparison between genotypes showed that only CG genotype of STAT4 rs10181656 polymorphism had a significant association with RA ( $p=0.005)$; however, our findings suggest that this genotype decreases the risk of susceptibility to $\mathrm{RA}(\mathrm{OR}=0.448,95 \% \mathrm{CI}=0.257-0.781)$. Our results showed no more association of the STAT4 rs10181656 polymorphism with $\mathrm{SSc}$ in this population $(p=0.357)$. Also, none of the $G G$, GC, CC genotypes or $\mathrm{G}$ or $\mathrm{C}$ alleles showed any significant differences between the $\mathrm{lcSSc}$ and $\mathrm{dcSSc}$ patient groups.

The demographic and clinical data of the RA patients are shown in Table 3. Agarose gel electrophoresis regards to RFLP is shown in Figure 1. There was no significant genotypic association with age, race and sex ( $p>0.05)$ (data not shown). Of the 120 RA patients tested for anti-CCP antibodies, $45.8 \%$ were positive and $54.2 \%$ were negative for the antibody. Also, $32.5 \%$ of RA patients were positive and $67.5 \%$ were negative for RF. The RA patients were classified according to anti-CCP status and no statistically significant difference was observed in genotype distributions $(p=0.873)$ in

\begin{tabular}{|c|c|c|c|c|c|c|c|}
\hline & \multicolumn{2}{|c|}{ Anti-CCP antibody positive } & \multicolumn{2}{|c|}{ Anti-CCP antibody negative } & \multirow[b]{2}{*}{$p$} & \multirow[b]{2}{*}{ OR } & \multirow[b]{2}{*}{$95 \% \mathrm{CI}$} \\
\hline & $\mathrm{n}$ & $\%$ & $\mathrm{n}$ & $\%$ & & & \\
\hline \multicolumn{8}{|c|}{ Genotype } \\
\hline $\mathrm{CC}$ & 50 & 67.6 & 24 & 32.4 & - & - & - \\
\hline CG & 20 & 62.5 & 12 & 37.5 & 0.613 & 0.80 & $0.337-1.901$ \\
\hline GG & 9 & 64.3 & 5 & 35.7 & 0.811 & 0.864 & $0.261-2.859$ \\
\hline \multicolumn{8}{|l|}{ Allele } \\
\hline $\mathrm{C}$ & 120 & 66.7 & 60 & 33.3 & - & 1 & - \\
\hline G & 38 & 63.3 & 22 & 36.7 & 0.637 & 1.158 & $0.629-2.130$ \\
\hline
\end{tabular}




\begin{tabular}{|c|c|c|c|c|c|c|c|}
\hline & \multicolumn{2}{|c|}{ RF antibody positive } & \multicolumn{2}{|c|}{$\mathrm{RF}$ antibody negative } & \multirow[b]{2}{*}{$p$} & \multirow[b]{2}{*}{ OR } & \multirow[b]{2}{*}{$95 \% \mathrm{CI}$} \\
\hline & $\mathrm{n}$ & $\%$ & $\mathrm{n}$ & $\%$ & & & \\
\hline \multicolumn{8}{|c|}{ Genotype } \\
\hline $\mathrm{CC}$ & 31 & 41.9 & 43 & 58.1 & - & - & - \\
\hline CG & 8 & 25.0 & 24 & 75.0 & 0.102 & 0.462 & 0.184-1.165 \\
\hline GG & 3 & 21.4 & 11 & 78.6 & 0.160 & 0.378 & $0.097-1.470$ \\
\hline \multicolumn{8}{|l|}{ Allele } \\
\hline $\mathrm{C}$ & 70 & 38.9 & 110 & 61.1 & - & 1 & - \\
\hline G & 14 & 23.3 & 46 & 76.7 & 0.031 & 0.478 & $0.244-0.933$ \\
\hline
\end{tabular}

positive patients compared with negative patients (Table 4). The RA patients were stratified into RF positive and negative groups and were analyzed in regard to their genotypes. No correlation was found except for $\mathrm{G}$ allele $(\mathrm{p}=0.031, \mathrm{OR}=0.478$, 95\% CI=0.244-0.933) (Table 5). Comparison of STAT4 rs7574865 genotypes in RA patients stratified with ACCP+/RF-, ACCP-/RF+ and $\mathrm{ACCP}+\mathrm{RF}+$ groups did not show any statistically significant association (Table 6).

When the SSc patients were divided into lcSSc and dcSSc patient groups, no statistically significant association was found between the two groups ( $p=0.694$ ) (Table 7).

Table 6. Comparison of STAT4 rs10181656 genotypes in RA patients stratified according to RF antibody

\begin{tabular}{|c|c|c|c|c|c|c|c|c|c|c|c|c|}
\hline & \multicolumn{2}{|c|}{$\mathrm{ACCP}+/ \mathrm{RF}-$} & \multicolumn{2}{|c|}{$\mathrm{ACCP}-/ \mathrm{RF}+$} & \multicolumn{2}{|c|}{$\mathrm{ACCP}+/ \mathrm{RF}+$} & \multicolumn{2}{|c|}{$\mathrm{ACCP}+/ \mathrm{RF}-$} & \multicolumn{2}{|c|}{$\mathrm{ACCP}-/ \mathrm{RF}+$} & \multicolumn{2}{|c|}{$\mathrm{ACCP}+/ \mathrm{RF}+$} \\
\hline & $\mathrm{n}$ & $\%$ & $\mathrm{n}$ & $\%$ & $\mathrm{n}$ & $\%$ & $p$ & OR & $p$ & OR & $p$ & OR \\
\hline \multicolumn{13}{|c|}{ Genotype } \\
\hline $\mathrm{CC}$ & 24 & 45.28 & 4 & 7.55 & 26 & 47.17 & - & - & - & - & - & 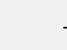 \\
\hline CG & 14 & 61.92 & 3 & 9.5 & 6 & 28.58 & 0.76 & 1.17 & 0.60 & 1.52 & 0.19 & 0.46 \\
\hline GG & 6 & 66.67 & 0 & 0 & 3 & 33.33 & 0.75 & 1.25 & 0.67 & 0.51 & 0.50 & 0.58 \\
\hline
\end{tabular}

STAT4: Signal transducer and activator of transcription 4; RA: Rheumatoid arthritis; RF: Rheumatoid factor; ACCP: Anti-cyclic citrullinated peptide; $\mathrm{RF}$ : Rheumatoid factor; OR: Odds ratio; Referred as subgroups of rheumatoid arthritis patients.

Table 7. Comparison of STAT4 rs10181656 genotypes in SSc patients stratified into lcSSc and dcSSc types

\begin{tabular}{|c|c|c|c|c|c|c|c|}
\hline & \multicolumn{2}{|c|}{ lcSSc } & \multicolumn{2}{|c|}{$\mathrm{dcSSc}$} & \multirow[b]{2}{*}{$p$} & \multirow[b]{2}{*}{ OR } & \multirow[b]{2}{*}{$95 \% \mathrm{CI}$} \\
\hline & $\mathrm{n}$ & $\%$ & $\mathrm{n}$ & $\%$ & & & \\
\hline \multicolumn{8}{|c|}{ Genotype } \\
\hline $\mathrm{CC}$ & 18 & 58.1 & 19 & 38.8 & - & - & - \\
\hline CG & 11 & 35.5 & 22 & 44.9 & 0.196 & 1.895 & $0.719-4.994$ \\
\hline GG & 2 & 6.5 & 8 & 16.3 & 0.120 & 3.789 & $0.707-20.297$ \\
\hline \multicolumn{8}{|l|}{ Allele } \\
\hline $\mathrm{C}$ & 47 & 75.8 & 60 & 61.2 & - & 1 & - \\
\hline G & 15 & 24.2 & 38 & 38.8 & 0.058 & 0.504 & $0.247-1.02$ \\
\hline
\end{tabular}

STAT4: Signal transducer and activator of transcription 4; SSc: Systemic sclerosis; lcSSc: Limited cutaneous systemic sclerosis; dcSSc: Diffuse cutaneous systemic sclerosis; OR: Odds ratio; CI: Confidence interval. Referred as subgroups of systemic sclerosis patients. 


\section{DISCUSSION}

One of the main reasons for the development of $\mathrm{RA}$ and $\mathrm{SSc}$ is the dysregulation of the immune system. The altered immune response in these two diseases is marked by an increased $T$ cell activation and the secretion of pro-inflammatory mediators. Several mechanisms regulate $\mathrm{T}$ cell activation differentiation, one of the more important of the mechanisms being the specific activation of gene transcription after cytokine stimulation. ${ }^{19}$ Signal transducers and activators of transcription (STAT) are a family of transcription factors that have been demonstrated to exert a fundamental role in driving $\mathrm{T}$ cell differentiation and signaling. ${ }^{20}$ Among the six described STAT proteins, STAT4 is implicated in the differentiation of type 1 and 17 helper $\mathrm{T}$ cells, two of the $\mathrm{T}$ cell subsets that are implicated in RA and SSc pathogenesis. ${ }^{9}$

Third intron of the STAT4 encompasses a few polymorphisms (rs18889341, rs7574865, rs8179673, and rs10181656) which have been reported to be associated with RA and SSc in some populations worldwide. ${ }^{21-25}$ However, this association remains to be challenging based on some studies conducted on the Southwestern Chinese Han, Turkish, African American and Southwestern Iran populations. ${ }^{26-28}$

Persistent and strong association between the STAT4 polymorphisms and RA and SSc in multiple independent and different ethnic populations suggested ${ }^{25}$ an important role of STAT4 gene in pathogenesis of SSc and RA in European and Asian populations and is considered a risk factor for both diseases.

In the current study, we confirmed the genetic association of STAT4 rs10181656 polymorphism with RA which was consistent with the previous reports ${ }^{28}$ in other ethnic populations. Comparison of genotypes showed that only CG genotype of STAT4 rs10181656 polymorphism had a statistically significant association with RA ( $p=0.005, \quad O R=0.448,95 \% \quad C I=0.257-0.781)$. We also did not find any statistically significant difference in allele frequency between RA patients and control group. Although contribution of the variant has been replicated, contradictory results have been reported (decreased G allele in Khuzestan province population and increased $\mathrm{G}$ allele in other populations). Due to the lack of power to detect OR below 1.5, the absence of an association may more likely be suggested. Also, the results indicated that rs10181656 polymorphism in the STAT4 gene was not associated with susceptibility to SSc in the Khuzestan province population. Therefore, the rs10181656 polymorphism is unlikely to be an influential variant related with susceptibility to RA and SSc in this population. RA and $\mathrm{SSc}$ are complex disorders and several factors would complicate their molecular genetics. Thus, the conflict between our finding and studies on some other populations might be due to the genetic background of the studied groups, small sample sizes, or an inadequate definition of the phenotypes. Furthermore, it should be noted that different environmental factors may have an effect on the development of diseases. Consequently, STAT4 gene may have different degrees of genetic risk among ethnic groups under different environmental exposure.

Although it seems that STAT4 rs10181656 polymorphism plays an effective role in several pathways involved in RA and SSc pathogenesis, the functional role of this polymorphism needs to be discovered. Due to its position in intron of STAT4 gene, it may be hypothesized that the SNP may be involved in the regulation of the splicing process. However, it is known that there are many ways by which introns can affect gene expression. Due to different interconnections between the various complexes involved in splicing and other post-transcriptional regulations, there are multiple opportunities for introns to affect expression by different mechanisms. For example, the presence of introns can increase the levels of mature messenger ribonucleic acid in the cytosol by impacting on the rate of transcription, nuclear export, and transcript stability. Also, intron-mediated enhancement is a phenomenon in which introns can elevate expression when present in the transcribed region. ${ }^{29-31}$ The mechanisms which are involved in this process of eukaryotic gene expression are not fully understood.

Our study has some limitations. Firstly, the small sample size may have limited the statistical power to detect any existing association. Thus, a larger number of patients and control subjects could be used to verify the results. Secondly, additional polymorphisms exist in the STAT4 
gene that might contribute to the susceptibility or activity of RA and SSc in this population.

In conclusion, our findings suggest an association between RA susceptibility and STAT4 rs10181656 polymorphism. However, no significant association was found between this polymorphism and SSc. Moreover, clinical features and disease activity parameters did not show any association with the polymorphism. Further studies can reveal the functional and molecular role of this polymorphism as well as its association with inflammatory diseases. ${ }^{32}$

\section{Acknowledgments}

This project was supported by Master's thesis grant from Shahid Chamran University of Ahvaz, Khuzestan (Iran). The authors wish to appreciate Rheumatology Clinic at Golestan Hospital of Ahvaz for providing blood samples of patient individuals.

\section{Declaration of conflicting interests}

The authors declared no conflicts of interest with respect to the authorship and/or publication of this article.

\section{Funding}

This study, as an academic scholarly work, was supported by the Master's thesis grant from Shahid Chamran University of Ahvaz, Iran.

\section{REFERENCES}

1. Davies AJ. Immunological tolerance and the autoimmune response. Autoimmun Rev 2008;7:53843.

2. Invernizzi $P$, Gershwin ME. The genetics of human autoimmune disease. J Autoimmun 2009;33:290-9.

3. Chomiczewska-Skóra DO, Trznadel-Grodzka E, Rotsztejn HE. Psoriasis as a disease associated with the immune system disorders. Cent Eur $\mathrm{J}$ Immunol 2013;38:129-33.

4. Wandstrat A, Wakeland E. The genetics of complex autoimmune diseases: non-MHC susceptibility genes. Nat Immunol 2001;2:802-9.

5. Hughes LB, Reynolds RJ, Brown EE, Kelley JM, Thomson B, Conn DL, et al. Most common singlenucleotide polymorphisms associated with rheumatoid arthritis in persons of European ancestry confer risk of rheumatoid arthritis in African Americans. Arthritis Rheum 2010;62:3547-53.

6. Kvien TK, Glennås A, Knudsrød OG, Smedstad LM, Mowinckel P, Førre O. The prevalence and severity of rheumatoid arthritis in Oslo. Results from a county register and a population survey. Scand J Rheumatol 1997;26:412-8.

7. MacGregor AJ, Snieder H, Rigby AS, Koskenvuo $\mathrm{M}$, Kaprio J, Aho $\mathrm{K}$, et al. Characterizing the quantitative genetic contribution to rheumatoid arthritis using data from twins. Arthritis Rheum 2000;43:30-7.

8. Varga J, Abraham D. Systemic sclerosis: a prototypic multisystem fibrotic disorder. J Clin Invest 2007;117:557-67.

9. Gu YS, Kong J, Cheema GS, Keen CL, Wick G, Gershwin ME. The immunobiology of systemic sclerosis. Semin Arthritis Rheum 2008;38:132-60.

10. Arnett FC, Cho M, Chatterjee S, Aguilar MB, Reveille JD, Mayes MD. Familial occurrence frequencies and relative risks for systemic sclerosis (scleroderma) in three United States cohorts. Arthritis Rheum 2001;44:1359-62.

11. Brand O, Gough S, Heward J. HLA, CTLA-4 and PTPN22: the shared genetic master-key to autoimmunity? Expert Rev Mol Med 2005;7:1-15.

12. Abbasi Z, Kazemi Nezhad SR, Pourmahdi-Broojeni M, Rajaei E. Association of PTPN22 rs2476601 Polymorphism with Rheumatoid Arthritis and Celiac Disease in Khuzestan Province, Southwestern Iran. Iran Biomed J 2017;21:61-6.

13. Watford WT, Hissong BD, Bream JH, Kanno Y, Muul L, O'Shea JJ. Signaling by IL-12 and IL-23 and the immunoregulatory roles of STAT4. Immunol Rev 2004;202:139-56.

14. Thierfelder WE, van Deursen JM, Yamamoto K, Tripp RA, Sarawar SR, Carson RT, et al. Requirement for Stat4 in interleukin-12-mediated responses of natural killer and T cells. Nature 1996;382:171-4.

15. Wurster AL, Tanaka T, Grusby MJ. The biology of Stat4 and Stat6. Oncogene 2000;19:2577-84.

16. Good SR, Thieu VT, Mathur AN, Yu Q, Stritesky GL, Yeh N, et al. Temporal induction pattern of STAT4 target genes defines potential for Th1 lineage-specific programming. J Immunol 2009;183:3839-47.

17. Tan FK, Zhou X, Mayes MD, Gourh P, Guo X, Marcum C, et al. Signatures of differentially regulated interferon gene expression and vasculotrophism in the peripheral blood cells of systemic sclerosis patients. Rheumatology (Oxford) 2006;45:694-702.

18. Korman BD, Alba MI, Le JM, Alevizos I, Smith JA, Nikolov NP, et al. Variant form of STAT4 is associated with primary Sjögren's syndrome. Genes Immun 2008;9:267-70.

19. Peng SL. Transcription factors in autoimmune diseases. Front Biosci 2008;13:4218-40.

20. Ross JA, Nagy ZS, Cheng H, Stepkowski SM, Kirken RA. Regulation of $\mathrm{T}$ cell homeostasis by JAKs and STATs. Arch Immunol Ther Exp (Warsz) 2007;55:231-45.

21. Liang YL, Wu H, Li PQ, Xie XD, Shen X, Yang XQ, et al. Signal transducer and activator of transcription 4 gene polymorphisms associated with rheumatoid 
arthritis in Northwestern Chinese Han population. Life Sci 2011;89:171-5.

22. Zhao Y, Liu X, Liu X, Su Y, Li Y, Zhang X, et al. Association of STAT4 gene polymorphism with increased susceptibility of rheumatoid arthritis in a northern Chinese Han subpopulation. Int J Rheum Dis 2013;16:178-84.

23. Rueda B, Broen J, Simeon C, Hesselstrand R, Diaz $\mathrm{B}$, Suárez $\mathrm{H}$, et al. The STAT4 gene influences the genetic predisposition to systemic sclerosis phenotype. Hum Mol Genet. 2009;18:2071-7.

24. Tsuchiya N, Kawasaki A, Hasegawa M, Fujimoto M, Takehara K, Kawaguchi Y, et al. Association of STAT4 polymorphism with systemic sclerosis in a Japanese population. Ann Rheum Dis 2009;68:1375-6.

25. Yi L, Wang JC, Guo XJ, Gu YH, Tu WZ, Guo G, et al. STAT4 is a genetic risk factor for systemic sclerosis in a Chinese population. Int $\mathrm{J}$ Immunopathol Pharmacol 2013;26:473-478.

26. Yüksel B, Ataman S, Evcik D, Ay S, Mumcuoğlu M, Erdoğan B. Is there an association between twoSTAT4 gene polymorphisms and rheumatoid arthritis in Turkish population? Arch Rheumatol 2014;29:20-7.
27. Kelley JM, Hughes LB, Malik A, Danila MI, Edberg Y, Alarcón GS, et al. Genetic variants of STAT4 associated with rheumatoid arthritis in persons of Asian and European ancestry do not replicate in African Americans. Ann Rheum Dis 2010;69:625-6.

28. Nezaratian N, Kazemi Nezhad SR, Hajjari M, Akhoond MR. Lack of association between STAT4 rs7574865 polymorphism and autoimmune diseases including rheumatoid arthritis and systemic sclerosis in Southwest Iran. Meta Gene 2017;14:64-8.

29. Rose $A B$. Introns as gene regulators: $A$ brick on the accelerator. Front Genet 2019;9:672.

30. Dahan O, Gingold H, Pilpel Y. Regulatory mechanisms and networks couple the different phases of gene expression. Trends Genet 2011;27:316-22.

31. Shaul O. How introns enhance gene expression. Int $\mathrm{J}$ Biochem Cell Biol 2017;91:145-155.

32. Sigurdsson S, Nordmark G, Garnier S, Grundberg E, Kwan T, Nilsson O, et al. A risk haplotype of STAT4 for systemic lupus erythematosus is over-expressed, correlates with anti-dsDNA and shows additive effects with two risk alleles of IRF5. Hum Mol Genet 2008;17:2868-76. 